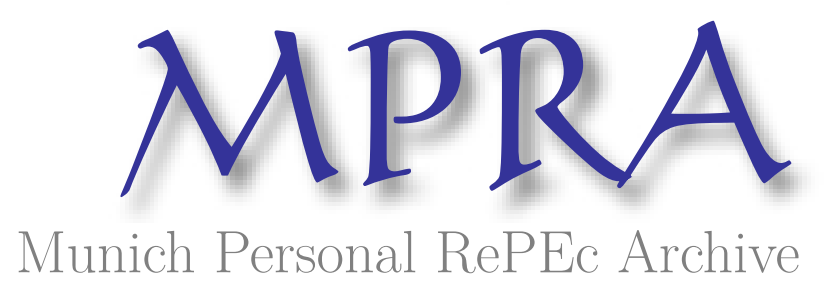

\title{
Heterogeneous Productivity Shocks, Elasticity of Substitution and Aggregate Fluctuations
}

Alessio, Moro and Rodolfo, Stucchi

February 2011

Online at https://mpra.ub.uni-muenchen.de/29032/

MPRA Paper No. 29032, posted 24 Feb 2011 18:45 UTC 


\title{
Heterogeneous Productivity Shocks, Elasticity of Substitution and Aggregate Fluctuations*
}

\author{
Alessio Moro ${ }^{\dagger} \quad$ Rodolfo Stucchi ${ }^{\ddagger}$
}

February 21, 2011

\begin{abstract}
We use a Dixit-Stiglitz setting to show that aggregate productivity fluctuations can be generated through changes in the dispersion of firms' productivity. When the elasticity of substitution among goods is larger than one, an increase in the dispersion raises aggregate productivity because firms at the top of the distribution produce most of output. When the elasticity is smaller than one, an increase in the dispersion reduces aggregate productivity because firms at the bottom of the distribution use most of inputs. We use individual firm data from Spanish manufacturing sectors to test the relationship between the dispersion of firms' productivity and aggregate productivity. The estimated coefficients are consistent with the predictions of the model: we find that an increase in the coefficient of variation of firms productivity of $1 \%$ increases aggregate productivity by $0.59 \%$ in sectors with an elasticity of substitution larger than one while the same increase in the coefficient of variation reduces aggregate productivity by $0.07 \%$ in sectors with an elasticity of substitution smaller than one.
\end{abstract}

JEL Classification: E13, E20, E30, E32.

Keywords: Heterogeneous Productivity Shocks, Elasticity of Substitution, Volatility, Aggregate Productivity.

\footnotetext{
${ }^{*}$ We would like to thank Esteban Jaimovich, Vincenzo Merella and Galo Nuño for the useful comments. The usual disclaimers apply.

${ }^{\dagger}$ Department of Economics, University of Cagliari.

${ }^{\ddagger}$ Inter-American Development Bank and Courant Research Centre "Poverty, Equity, and Growth in Developing Countries", University of Gottingen.
} 


\section{Introduction}

There is a growing literature on the ability of models with a large number of sectoral shocks to generate aggregate fluctuations. The basic idea is that shocks are transmitted across sectors through input-output relations so that a shock to a particular sector can lead to comovement of other sectors that purchase intermediate goods from it, as in Long and Plosser (1983). On this point, Lucas (1981) and Dupor (1999) suggest that when the economy is sufficiently disaggregated, independent sectoral shocks wash out in the aggregate because of the law of large numbers. Instead, Horvath (1998), and in particular Carvalho (2009), show that the response of the aggregate economy to a large number of sectoral shocks depends on the input-output structure of the economy.

In this paper we study the relationship between idiosyncratic productivity shocks and aggregate productivity fluctuations from a demand side perspective. We first use a Dixit-Stiglitz model of demand to show that when the elasticity of substitution among a large number of goods is different from one, aggregate productivity is different from the average productivity of firms producing those goods. This implies that even if the deterministic part of firms productivity is equal to one and firms receive i.i.d. shocks from a common probability distribution function, aggregate productivity is different from one.

This result follows from the fact that the elasticity of substitution determines consumers' willingness to change the purchases ratio of two goods when the price ratio of those goods changes. If the elasticity is high, consumers switch from one good to another for small price changes. When the elasticity is small, it takes high price differentials to induce consumers to slightly change the bundle of goods they are consuming. Thus, a low elasticity of substitution implies that production is distributed evenly across producers. If this is the case, low productivity firms have a large impact on the productive capacity of the economy and therefore aggregate productivity is low. On the other hand, when the elasticity of substitution is high, output is produced mostly by high productivity firms and aggregate productivity is large.

An implication of an elasticity of substitution different from one is that, even when the mean of the distribution does not change, changes in the shape of the distribution of firms productivity have the same effect of an 
"aggregate" shock hitting the productivity of all firms. Although this paper does not provide a theory of the time variation of the distribution of firms' productivity, there is little reason to suppose that this distribution is stable over time. On the empirical side, Bloom et al. (2009) provide evidence suggesting that the variance of establishment, firm and industry level shocks in the U.S. is countercyclical. Bachman and Bayer (2009), using a panel of public and private German firms in manufacturing and retail, find that the variance of innovations to firms' productivity increases in recessions. In this paper, we provide evidence that the variance of the distribution of firms productivity in Spanish manufacturing sectors varies sensibly over time. It follows that the interaction between a time varying productivity distribution and an elasticity of substitution different from one provides a source of fluctuations in aggregate productivity without the need to assume a common (aggregate) shock to the productivity of all firms, or an input-output matrix that transmits sectoral shocks across sectors.

A crucial point here is that, depending on the elasticity of substitution, an increase in the dispersion of firms' productivity can have a positive or a negative effect on aggregate productivity. When the elasticity is smaller than one, an increase in the dispersion has a negative effect, while the opposite holds with an elasticity larger than one. This happens because an increase in the dispersion implies that there are more high productive firms and more low productive firms. If the elasticity of substitution is high, most productive firms employ most of inputs and produce most of output so when their number increases aggregate productivity also increases. When the elasticity of substitution is low, demand tends to be distributed evenly among producers, so an increase in the number of low productive firms reduces aggregate productivity because these firms use most of inputs.

To test the predictions of the model we use data from 18 Spanish manufacturing sectors. We first estimate the elasticity of substitution among goods in each sector. This is smaller than one in 14 sectors and larger than one in 4 sectors. With the estimated elasticity of substitution we are able to construct, for each sector, the relevant measure of aggregate productivity. According to the model, sectors with an elasticity of substitution larger (lower) than one show an increase (decrease) in aggregate productivity when the dispersion of the productivity distribution increases. We test this implication in a regression framework. We regress aggregate productivity of each sector on the coefficient of variation of productivity in each sector and the interaction between the coefficient of variation and a dummy variable 
that takes value one if the sector has an elasticity of substitution larger than one. The estimated coefficients are consistent with the predictions of the model; we find that an increase of $1 \%$ in the coefficient of variation of the distribution of firms' productivity increases aggregate productivity by $0.59 \%$ in sectors with an elasticity of substitution larger than one while the same increase in the coefficient of variation reduces aggregate productivity by $0.07 \%$ in sectors with an elasticity of substitution smaller than one.

We are not the first to investigate the effects of a time varying dispersion of firms' productivity on aggregate fluctuations. Bloom et al. (2009) and Bachman and Bayer (2009) provide fully-fledged general equilibrium models that allow to study these effects. Bloom et al. (2009) show that when labor and capital adjustment costs are present, uncertainty shocks make firms more cautious, thus delaying hiring and investment, which in turn depresses aggregate productivity and economic activity. Bachman and Bayer (2009) instead, stress the "news" role of changes in uncertainty in shaping aggregate fluctuations. Compared to these contributions, we identify a new channel through which changes in the dispersion of firms' productivity can lead to aggregate fluctuations. This is solely grounded in the elasticity of substitution among goods.

This paper also contributes to two other strands of the literature: the one that studies the existence of persistent productivity differences among firms and the one that studies how the distribution of resources among firms affects aggregate productivity. Within the former, a closely related paper is Syverson (2004), who investigates the role of the elasticity of substitution on observed differences in plant level productivity. He points out, focusing on the concrete market, that barriers to substitutability of any kind (spatial, physical or brand driven) among producers, allow less productive firms to survive, thus decreasing average productivity. Compared to Syverson (2004) we focus on the effect of goods substitutability on aggregate fluctuations.

In the increasing literature on the distribution of resources across firms and aggregate productivity, Restuccia and Rogerson (2008) show how a misallocation of resources reduces aggregate TFP; Guner et al. (2008) analyze the role of restrictions on the size of firms for aggregate productivity; Hsie and Klenow (2009) provide a quantitative evaluation of the impact of misallocation on aggregate TFP. In contrast with these contributions, we focus on an economy with no distortions. We show that changes in the distribution of resources across firms can have different effects on aggregate productivity 
depending on the elasticity of substitution among goods.

The remaining of the paper is as follows: section 2 describes the model; section 3 reports the quantitative results; section 4 presents some robustness checks; and finally, section 5 concludes.

\section{The Model}

\subsection{Sectors and Firms}

We consider an economy with $n$ sectors. Good $i$ is produced in sector $i$. In turn, sector $i$ is composed of a continuum of atomless sectors indexed by $j \in[0,1]$. In each sector $j$ there is perfect competition and the representative firm in $j$ produces output using the following production function

$$
y_{i j}=A_{i j} N_{i j}
$$

where $N_{i j}$ is the amount of labor used in production and $A_{i j}$ is a firm specific productivity term. It follows that the representative firm $j$ maximizes profits according to the zero profit condition

$$
p_{i j}=\frac{w}{A_{i j}}
$$

where $w$ is the wage rate and $p_{i j}$ the price of output.

\subsection{Demand and Equilibrium}

We assume a Dixit-Stiglitz aggregator of the goods produced in sector $i$

$$
C_{i}=\left[\int_{0}^{1} c_{i j}^{\frac{\theta_{i}-1}{\theta_{i}}} d j\right]^{\frac{\theta_{i}}{\theta_{i}-1}}
$$

$C_{i}$ represents the total demand of output produced in sector $i$. This is determined by the demand towards that sector of final consumption, investment and intermediate goods. ${ }^{1}$

\footnotetext{
${ }^{1}$ In the empirical part in section 3 we consider only manufacturing sectors. Thus, although we have data only on output and not on demand, it is reasonable to assume that each sector faces a demand of final consumption, investment goods, and intermediate goods.
} 
The maximization of (3), subject to a standard budget constraint

$$
\int_{0}^{1} p_{i j} c_{i j} d j \leq W
$$

where $W$ is a positive constant, implies that the demand function for firm $j$ in sector $i$ is

$$
c_{i j}=\left(\frac{p_{i j}}{P_{i}}\right)^{-\theta_{i}} C_{i}
$$

In equilibrium, market clearing implies that

$$
y_{i j}=c_{i j},
$$

for each $j$ in $i$. Finally, the demand function (4) implies that the price of $C_{i}$ is

$$
P_{i}=\left[\int_{0}^{1} p_{i j}^{1-\theta_{i}} d j\right]^{\frac{1}{1-\theta_{i}}} .
$$

\subsection{Aggregate and Average productivity}

For each sector $i$, the zero profit condition implies that

$$
P_{i} C_{i}=w N_{i}
$$

where $N_{i}=\int_{0}^{1} N_{i j} d j$ is the total amount of labor used in sector $i$. By applying (2) to (6) it follows that

$$
\left[\int_{0}^{1} p_{i j}^{1-\theta_{i}} d j\right]^{\frac{1}{1-\theta_{i}}}=w\left[\int_{0}^{1}\left(\frac{1}{A_{i j}}\right)^{1-\theta_{i}} d j\right]^{\frac{1}{1-\theta_{i}}}
$$

and

$$
\frac{w}{P_{i}}=\left[\int_{0}^{1} A_{i j}^{\theta_{i}-1} d j\right]^{\frac{1}{\theta_{i}-1}} .
$$

Next, by using (8) in (7) we obtain

$$
C_{i}=\left[\int_{0}^{1} A_{i j}^{\theta_{i}-1} d j\right]^{\frac{1}{\theta_{i}-1}} N_{i}
$$

Equation (9) represents the aggregate production function of sector $i$, as it maps the total amount of labor used in production in that sector into 
total output. In (9), the productivity term $\left[\int_{0}^{1} A_{i j}^{\theta_{i}-1} d j\right]^{\frac{1}{\theta_{i}-1}}$ depends on individual firms productivity $A_{i j}$, and on the elasticity of substitution $\theta_{i}$ among goods produced in sector $i .^{2}$ Note that

$$
\left[\int_{0}^{1} A_{i j}^{\theta_{i}-1} d j\right]^{\frac{1}{\theta_{i}-1}}=E\left[A_{i j}^{\theta_{i}-1}\right]^{\frac{1}{\theta_{i}-1}}
$$

represents the moment of order $\theta_{i}-1$ of the distribution of $A_{i j}$, raised to the power of $\frac{1}{\theta_{i}-1}$. We define $A_{i}=E\left[A_{i j}^{\theta_{i}-1}\right]^{\frac{1}{\theta_{i}-1}}$ aggregate productivity of sector $i$, to differentiate it from average productivity $\tilde{A}_{i}=\int_{0}^{1} A_{i j} d j$ within the sector. Thus, depending on the elasticity of substitution among goods, the productivity distribution implies different levels of aggregate productivity.

\subsection{Implications}

Equation (9) shows that aggregate productivity is a geometric, and not a linear, mean of individual productivity. Thus, when $\theta_{i} \neq 1$, the linear aggregation of firms' productivity does not provide an appropriate measure of aggregate productivity. To see the importance of $\theta_{i}$ in shaping aggregate productivity, assume that the productivity of firm $j$ in $i$ is $A_{i j}=e^{\varepsilon_{j}}$, where each $\varepsilon_{j}$ is an i.i.d. shock from a $N\left(0, \sigma^{2}\right)$ distribution. Thus, if the shock $\varepsilon_{j}$ is zero, the productivity of firm $j$ is equal to one. In this case, it can be shown that aggregate productivity in (10) becomes

$$
A_{i}=e^{\left(\theta_{i}-1\right) \sigma^{2} / 2}
$$

Panel (a) of Figure 1 reports aggregate productivity $A_{i}$ for values of the standard deviation $\sigma$ from 0.1 to 0.9 , when $\theta_{i}=0.5$. Panel (b) of Figure 1 reports the same measure for $\theta_{i}=1.5$. In both graphs we also report the level of aggregate productivity when $\varepsilon_{j}=0$ for all firms, which is one in both cases.

As equation (11) makes clear, the value of the elasticity of substitution $\theta_{i}$ determine the effect that a change in the dispersion of firms' productivity has on aggregate productivity. With a unitary elasticity of substitution, $\theta_{i}=1$, changes in the dispersion of firms' productivity have no effect on aggregate productivity. When $\theta_{i}>1$ most productive firms produce a large part of

\footnotetext{
${ }^{2}$ Note that, as we are assuming that labor is the only input in production, aggregate labor productivity and aggregate TFP coincide.
} 
output in the economy. When the variance of the productivity distribution increases, the number of firms in the tails of the distribution increases, implying that there are more high productive, and more low productive firms. As output is produced mainly by high productive firms when $\theta_{i}>1$, these firms attract most of labor, and an increase in the variance raises aggregate productivity. When $\theta_{i}<1$ production tends to be divided evenly among producers in the economy. To see why an increase in the variance of the productivity distribution reduces aggregate productivity when $\theta_{i}<1$, consider the limit case in which $\theta_{i}$ tends to zero (Leontief demand). In this case, production is divided equally among producers, regardless of prices. In this situation, the least productive firm determines the amount of output demanded to (and thus produced by) all firms. When the variance of the productivity distribution increases the number of firms at the bottom of the distribution increases. As the elasticity of substitution is small, these firms attract most of the labor input in the economy and aggregate productivity declines.

Thus, when the elasticity of substitution is different from one, changes in aggregate productivity can be the result of changes in the shape of the productivity distribution (in the example above a change in the variance of the distribution) instead of changes in the productivity of each firm (common aggregate shocks). In the next section we investigate whether the interaction between changes in the distribution of productivity shocks and an elasticity of substitution different from one has a quantitatively relevant impact on aggregate productivity fluctuations.

\section{Quantitative Analysis}

The main prediction of the model is that a time-varying dispersion in firms' productivity induces aggregate productivity fluctuations when the elasticity of substitution among goods is different from one. In this section we use individual firm level data to test the prediction that an increase in the dispersion of firms' productivity increases aggregate productivity in sectors in which the elasticity of substitution is larger than one while it decreases it when the elasticity is smaller than one. We use data from the Survey on Business Strategies (Encuesta sobre Estrategias Empresariales, ESEE) which is an annual survey on a representative sample of Spanish manufacturing firms. The sample period is 1991-2005. A description of the dataset 
is provided in the Data Appendix. ${ }^{3}$

We first estimate the elasticity of substitution $\theta_{i}$ for each of the 18 sectors in our dataset $(i=1,2, \ldots, 18)$. Note that for each sector $i$, the demand function of firm $j$ in the model, equation (4), can be written in logs as $\log c_{i j t}=-\theta_{i} \log p_{i j t}+\theta_{i} \log P_{i t}+\log C_{i t}$. To obtain an estimating equation at the firm level we replace $\theta_{i} \log P_{i t}+\log C_{i t}$ by an industry specific set of time dummy variables, $\eta_{i t}$. By doing this we control for every non-observed time varying factor that affects homogeneously all firms in the same sector. Additionally, we include a non-observed time invariant term, $\mu_{i j}$ that captures firm specific charcteristics (for instance differences in the geographical position). Finally, we include a random term $v_{i j t}$ that captures shocks that are not correlated with $p_{i j t}$. Therefore, for each sector $i$ we estimate

$$
\log c_{i j t}=-\theta_{i} \log p_{i j t}+\eta_{i t}+\mu_{i j}+v_{i j t}, \quad i=1,2, \ldots, 18,
$$

where $c_{i j t}$ is output of firm $j$ in period $t$ and $p_{i j t}$ its price. ${ }^{4}$ The output measure we use is the value of production (i.e. sales) in period $t$ deflated using a firm specific price index. The price index is the same we use as regressor and is constructed as a Paasche-type price index computed from the percentage price changes that firms report to have made in the markets in which they operate. Because of the unobserved fixed effect, $\mu_{i j}$, we estimate (12) using the within group estimator.

Table 1 reports the estimation of $\theta_{i}$ for each industry $i$. We find a statistically significant elasticity of substitution in 17 sectors. Only "Other Manufactured Products" displays a non-significant elasticity, probably due to the heterogeneity of products in the sector. Of the remaining sectors, 4 display a $\theta_{i}$ larger than one and 13 a $\theta_{i}$ smaller than one.

Next, we compute the coefficient of variation of the distribution of firms productivity in each sector for each year of the sample period 1991-2005. We use the coefficient of variation instead of the variance of the distribution to have a comparable measure of dispersion across sectors. The measure that we use for firm level productivity is output over the labor input. Output is measured as the value of production (i.e. sales). ${ }^{5}$ Labor is measured

\footnotetext{
${ }^{3}$ See also Doraszelski and Jaumandreu (2009), Escribano and Stucchi (2010) and Dolado and Stucchi (2010) for additional details on the dataset.

${ }^{4}$ As in the model, subindex $i j$ means that firm $j$ belongs to sector $i$. In the dataset, firms never move from one sector to another.

${ }^{5}$ This is the standard measure of output in the productivity literature at disaggregated
} 
as hours worked. Table 2 reports the mean over time of the coefficient of variation of each sector, and the standard deviation (over time) of the coefficient of variation. The third column of Table 2 reports the ratio of the standard deviation and the mean. Excluding sector 18, this ratio ranges from 6\% (Wood and Furniture) to 36\% (Office Machinery, Data Processing Machinery, etc.).

Tables 1 and 2 provide empirical evidence about the two basic ingredients of our model: (a) the elasticity of substitution among goods is different from one in all sectors, ranging from 0.471 to 2.487 ; and (b) the dispersion of firms productivity shows a certain degree of time variation in all sectors. Our model suggests that in sectors in which the elasticity of substitution among goods is larger than one, an increase in the dispersion of firms' productivity increases aggregate productivity, while the opposite holds when the elasticity of substitution is smaller than one. This prediction can be formally tested by estimating the following regression

$$
\log A_{i t}=\alpha_{1} \log C V_{i t}+\alpha_{2} \log C V_{i t} \times 1\left[\theta_{i}>1\right]+\rho_{t}+\phi_{i}+u_{i t}
$$

where $A_{i t}$ is the aggregate level of productivity of sector $i$ in period $t$, constructed using the discrete counterpart of (10) and the value of $\theta_{i}$ reported in Table $1, C V_{i t}$ is the coefficient of variation of firms' productivity in sector $i$ and period $t, 1[\cdot]$ is an indicator function (i.e., $1\left[\theta_{i}>1\right]$ is a dummy variable that takes value one if $\theta_{i}$ is larger than one). ${ }^{6}$ Finally, $\rho_{t}$ represents unobserved factors that affect in the same way the productivity of all sectors (for instance an economy wide trend in productivity) and $\phi_{i}$ is a set of time-invariant unobserved characteristics of each sector.

Regarding the parameters of equation (13), the model implies $\alpha_{1}<0$, $\alpha_{2}>0$, and $\left|\alpha_{2}\right|>\left|\alpha_{1}\right|$. Table 3 shows the fixed-effect estimates of equation (13). Both the sign and the magnitude of the estimated coefficients are in line with the theoretical model, suggesting that the main predictions are supported by the data even after controlling for unobserved sectors fixedeffects and other factors that affect in the same way the productivity of all sectors.

From a quantitative perspective, the estimated $\alpha_{1}$ and $\alpha_{1}+\alpha_{2}$ represent the elasticity of aggregate productivity to the coefficient of variation when

level. See for instance Griffith, Haskel and Neely (2006).

${ }^{6} \operatorname{In}(13), A_{i}=\left[\sum_{j=1}^{N_{i}} \frac{A_{i j}^{\theta_{i}-1}}{N_{i}}\right]^{\frac{1}{\theta_{i}-1}}$, where $N_{i}$ is the number of firms in sector $i$. 
$\theta_{i}$ is smaller and larger than one, respectively. Results in Table 3 suggest that the response of aggregate productivity is quantitatively significant when $\theta_{i}>1$, while it is close to zero when $\theta_{i}<1$. In the first case, an increase in the coefficient of variation of $1 \%$ increases aggregate productivity by $0.587 \%$. In the second case, the same increase in the coefficient of variation reduces aggregate productivity by only $0.069 \%$. Consider for instance the sector Ferric and Non Ferric Metals, which displays a coefficient of variation of 0.725 and a standard deviation of the coefficient of variation of 0.067 with a ratio between the latter and the former of $9 \%$. As the elasticity of substitution in that sector is larger than one, the estimation in table 3 implies that an increase in the coefficient of variation of $9 \%$ leads to an increase in aggregate productivity of $5.2 \%$. Thus, our results suggest that commonly measured aggregate productivity fluctuations can be in part the results of a time-varying dispersion of firms' productivity.

\section{Robustness checks}

In this section we present three robustness exercises. First, we consider the possibility that the results might be affected by the time-varying number of firms in the panel. That is, changes in the variance of the distribution of firms' productivity might be determined by the entry and exit of firms in the sample over time. To account for this possibility, we consider the balanced panel of firms with information for all the 15 years of the sample period. ${ }^{7}$ Table 4 shows that estimation results are similar qualitatively and quantitatively to those obtained in Table 3 with the unbalanced panel.

Second, we find that there are four sectors in which is not possible to reject the null hypothesis that $\theta$ is equal to one. ${ }^{8}$ Thus, we estimate equation (13) considering only those sectors for which the estimation of $\theta$ is statistically significant different from one. Table 5 shows the results. The sign, magnitude, and statistical significance of the estimated coefficients is very close to those of Table 3 .

Finally, note that equation (2) implies that the supply function is an horizontal line. Thus, the theory suggests that in estimating (12) we do not face the endogeneity and identification problems typically encountered when

\footnotetext{
${ }^{7}$ There are 147 firms reporting information during the entire sample period.

${ }^{8}$ These sectors are: 3) Chemical Products, 4) Metallic Products, 12) Beverages, and 17) Plastic Products and Rubber.
} 
estimating demand functions, because the price $p_{i j}$ does not depend on the quantity $q_{i j}$. Here we depart from the assumption of an horizontal supply function and consider the possibility that the price can be endogenous in the estimation of (12). In this case, the OLS estimates of $\theta_{i}$ in Table 1 are inconsistent. This affects the estimates in equation (13) and therefore the relationship between the coefficient of variation and aggregate productivity. Thus, it is necessary to estimate equation (12) using instrumental variables. To instrument the price $p_{i j}$ in (12) we use a supply shifter, namely, the price of intermediate goods purchased by firm $i j$.

The first column in Table 6 shows the coefficient of the price of intermediate goods in the price equation (first stage equation). As expected, an increase in the price of intermediate goods is translated into an increase in the price of the final good and therefore the coefficient of the price of intermediates is positive. ${ }^{9}$ Columns 3 and 4 in Table 6 shows the estimated values of $\theta$ and their standard errors. Compared to the OLS, the IV estimation implies that 4 sectors display a negative $\theta_{i}$, which has no economic interpretation. Of the remaining sectors 8 display and elasticity larger than one and 6 an elasticity smaller than one.

We perform three robustness exercises depending on the value of the estimated $\theta_{i}$ and the goodness of the instrument. First, we do not consider those sectors with an estimate of $\theta_{i}$ lower than zero. Second, we also exclude those sectors that have an OLS estimate of $\theta_{i}$ statistically lower than one and an IV estimate of $\theta_{i}$ statistically larger than one. Finally, we also exclude those sectors for which the price of intermediate goods is not a good instrument for the final good price $p_{i j}$. Table 7 shows the sectors that are excluded in each exercise and the reason for the exclusion.

Table 8 shows the estimates of equation (13) in each exercise. The main message of this table is that the estimated coefficients are robust in terms of sign even when the number of observations in each exercise is sequentially lower. Quantitatively, the effect of an increase in the variance is again larger in sectors with an elasticity of substitution larger than one with respect to sectors that display an elasticity smaller than one. Thus, although the coefficient $\alpha_{1}$ loses statistical significance across exercises because we are reducing the number of observation, the relationship between aggregate

\footnotetext{
${ }^{9}$ The coefficient is negative only in sector 12 (Beverages). However, it is not statistically different from zero.
} 
productivity and the coefficient of variation appears robust.

\section{Conclusions}

We presented a new channel that can plausibly generate fluctuations in aggregate productivity. This is given by the interaction between a timevarying dispersion of firms' productivity and an elasticity of substitution among goods different from one. The empirical evidence that we provide suggests that the elasticity of substitution is different from one in manufacturing sectors, and that the dispersion of firms' productivity varies sensibly over time. Thus, the mechanism proposed seems to have empirical relevance, although this appears mostly restricted to the case in which the elasticity of substitution is larger than one.

We also showed that, depending on the elasticity of substitution, the dispersion of firms' productivity can be positively or negatively related to the level of aggregate productivity. This suggests that the co-existence of firms with heterogeneous productivity is not necessarily detrimental for aggregate productivity: if the elasticity of substitution is high, the co-existence of very high and very low productive firms implies a high aggregate productivity. This is not the case when the elasticity of substitution is low. In this case, the more homogeneous is productivity across firms, the larger aggregate productivity. 


\section{Data Appendix}

We use individual firm-level data from the Survey on Business Strategies (Encuesta sobre Estrategias Empresariales, ESEE) which is an annual survey on a representative sample of Spanish manufacturing firms. The sample period is 1991-2005. In the base year, firms were chosen according to a sampling scheme where weights depend on their size category. All firms with more than 200 employees are surveyed and their participation rate in the survey reached approximately $70 \%$ of the overall population of firms in this category. Likewise, firms with 10 to 200 employees were surveyed according to a random sampling scheme with a participation rate close to $5 \%$. This selection scheme was applied to each industry in the manufacturing sector.

Another important feature of the survey is that the initial sample properties have been maintained in all subsequent years. Newly created and exiting firms have been recorded in each year with the same sampling criteria as in the base year. Therefore, due to this entry and exit process, the dataset is an unbalanced panel of firms. The number of firms with information on all the variables of interest is 3,277 and the number of observations is 18,247 . The number of firms with $1,2,3, \ldots, 15$ observations is 899,359 , $239,190,195,221,136,127,170,120,122,103,116,133,147$, respectively. 


\section{References}

[1] Bachman, R. and Bayer, R. (2009), "Firm-specific productivity risk over the business cycle: facts and aggregate implications", Yale mimeo.

[2] Bloom, N., Floetotto, M. and Jaimovich, N., (2009), "Really Uncertain Business Cycle", manuscript.

[3] Carvalho, V. M., (2009), "Aggregate Fluctuations and The Network Structure of Intersectoral Trade", manuscript, University of Chicago.

[4] Dolado, J. J., and Stucchi, R., (2009), "Do temporary contracts affect TFP? Evidence from Spanish firms," CEPR Discussion Paper No. 7055.

[5] Doraszelski, U. and Jaumandreu, J., (2009), "R\&D and Productivity: Estimating Endogenous Productivity," Harvard University Working Paper.

[6] Dupor, B., (1999), "Aggregation and Irrelevance in Multi-Sector Models", Journal of Monetary Economics, 43, 391-409.

[7] Escribano, A., and Stucchi, R., (2009), "Catching up in firms' Total Factor Productivity through the business cycle: Evidence from Spanish manufacturing surveys", mimeo.

[8] Guner, N., Ventura, G. and Xu, Y., (2008), "Macroeconomic Implications of Size Dependent Policies", Review of Economic Dynamics, 11(4), 721-744.

[9] Griffith, R., Haskel, J. and Neely, A., (2006), "Why is Productivity so Dispersed?", Oxford Review of Economic Policy, Vol. 22, Issue 4, pp. 513-525.

[10] Horvath, M., (1998), "Cyclicality and Sectoral Linkages: Aggregate Fluctuations from Independent Sectoral Shocks", Review of Economic Dynamics, 1, 781-808.

[11] Hsieh, C-T., and Klenow, P. J., (2009), "Relative Prices and Relative Prosperity", Quarterly Journal of Economics, CXXIV, 1403-1448.

[12] Long Jr., J.B. and Plosser, C. I., (1987), "Sectoral versus Aggregate Shocks", American Economic Review, 77, 333-36.

[13] Lucas, R.E., (1981), "Understanding Business Cycles", in Studies in Business Cycle Theory. MIT Press. 
[14] Restuccia, D. and Rogerson, R., (2008), "Policy Distortions and Aggregate Productivity with Heterogeneous Plants", Review of Economic Dynamics, 11(4), 707-720.

[15] Syverson, C., (2004) "Market Structure and Productivity: A Concrete Example", Journal of Political Economy, 112(6), 1181-1222. 


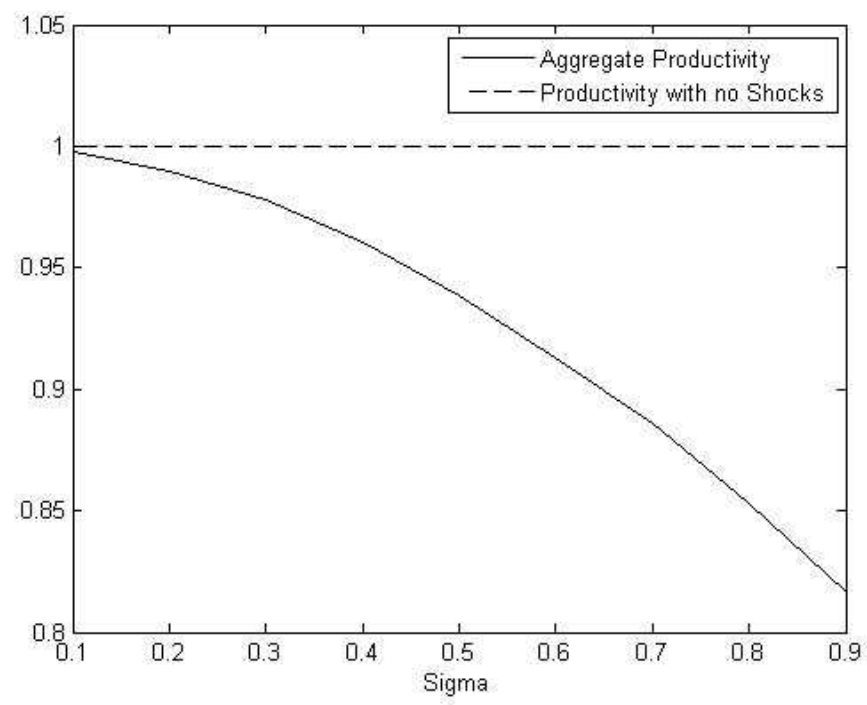

(a) $\theta=0.5$

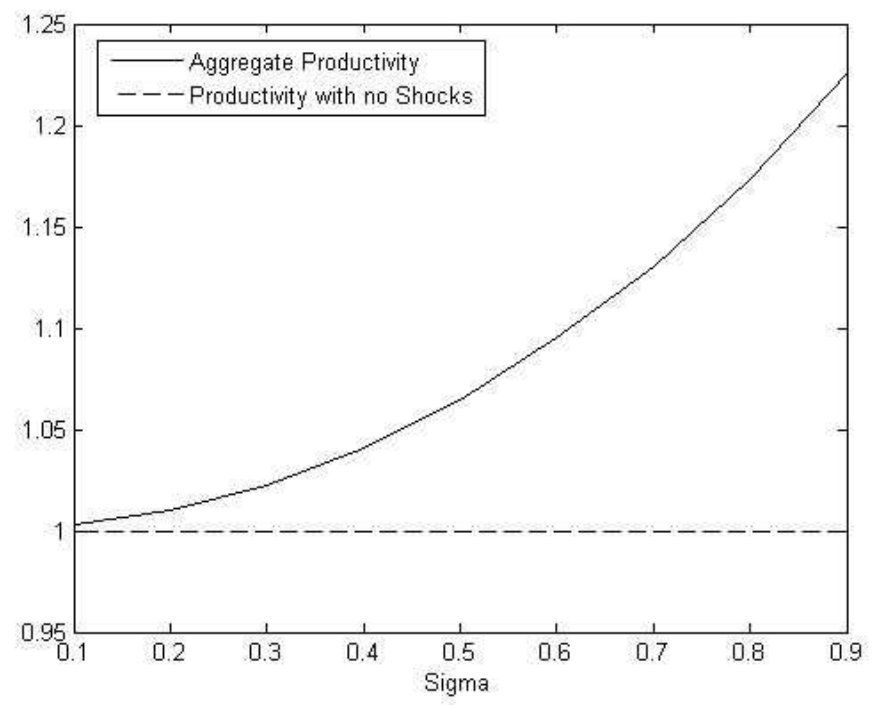

(b) $\theta=1.5$

Figure 1: Average and Aggregate Productivity for different values of $\sigma$ 
Table 1: Estimation of $\theta$

\begin{tabular}{llccc}
\hline \hline & Sectors & coef & sd & t \\
\hline 1 & Ferric and Non Ferric Metals & 1.339 & 0.094 & 14.26 \\
2 & Non Metallic Products & 0.476 & 0.094 & 5.07 \\
3 & Chemical Products & 0.989 & 0.112 & 8.87 \\
4 & Metallic Products & 0.962 & 0.109 & 8.81 \\
5 & Agricultural and Industrial Machinery & 0.723 & 0.140 & 5.18 \\
6 & Office Machinery, Data Processing Machinery, etc. & 2.487 & 0.293 & 8.49 \\
7 & Electrical Material and Electrical Accessories & 0.808 & 0.115 & 7.03 \\
8 & Vehicles and Motors & 0.510 & 0.196 & 2.60 \\
9 & Other Transport Material & 1.519 & 0.437 & 3.48 \\
10 & Meat and Meat Products & 0.487 & 0.106 & 4.61 \\
11 & Food and Tobacco & 0.471 & 0.081 & 5.84 \\
12 & Beverages & 0.921 & 0.211 & 4.36 \\
13 & Textiles and Apparels & 0.591 & 0.097 & 6.08 \\
14 & Leather products and shoes & 0.578 & 0.281 & 2.06 \\
15 & Wood and Furniture & 0.797 & 0.150 & 5.33 \\
16 & Paper, Paper Products and Printing Products & 0.642 & 0.061 & 10.53 \\
17 & Plastic Products and Rubber & 1.011 & 0.109 & 9.28 \\
18 & Other Manufactured Products & -0.449 & 0.291 & -1.54 \\
\hline \hline
\end{tabular}


Table 2: The dispersion of firms' productivity by industry

\begin{tabular}{llccc}
\hline \hline & Sectors & $\mathrm{CV}^{(1)}$ & $\mathrm{sd}(\mathrm{CV})^{(2)}$ & Ratio $^{(3)}$ \\
\hline 1 & Ferric and Non Ferric Metals & 0.725 & 0.067 & 0.09 \\
2 & Non Metallic Products & 0.636 & 0.076 & 0.12 \\
3 & Chemical Products & 0.646 & 0.101 & 0.16 \\
4 & Metallic Products & 0.603 & 0.072 & 0.12 \\
5 & Agricultural and Industrial Machinery & 0.614 & 0.060 & 0.10 \\
6 & Office Machinery, Data Processing Machinery, etc. & 0.951 & 0.340 & 0.36 \\
7 & Electrical Material and Electrical Accessories & 0.640 & 0.060 & 0.09 \\
8 & Vehicles and Motors & 0.672 & 0.149 & 0.22 \\
9 & Other Transport Material & 0.762 & 0.118 & 0.15 \\
10 & Meat and Meat Products & 0.702 & 0.073 & 0.10 \\
11 & Food and Tobacco & 0.977 & 0.073 & 0.07 \\
12 & Beverages & 0.574 & 0.077 & 0.13 \\
13 & Textiles and Apparels & 0.816 & 0.054 & 0.07 \\
14 & Leather products and shoes & 0.606 & 0.090 & 0.15 \\
15 & Wood and Furniture & 0.595 & 0.035 & 0.06 \\
16 & Paper, Paper Products and Printing Products & 0.693 & 0.065 & 0.09 \\
17 & Plastic Products and Rubber & 0.512 & 0.036 & 0.07 \\
18 & Other Manufactured Products & 0.816 & 0.354 & 0.43 \\
\hline \hline
\end{tabular}

Notes: (1) Mean over time, $C V_{i}=1 / T \sum_{t=1}^{T} C V_{i t}(i=1,2, \ldots, 18)$, (2) Standard deviation over time, (3) Ratio $s d\left(C V_{i t}\right) / C V_{i}$. 
Table 3: The relationship between aggregate productivity and the dispersion of productivity

\begin{tabular}{lcc}
\hline \hline & $\begin{array}{c}\text { coef } \\
\text { (s.e) }\end{array}$ & $\begin{array}{c}\text { One side } \\
\text { p-value }\end{array}$ \\
\hline Coef. of variation of productivity (in logs) & -0.069 & 0.098 \\
& $(0.052)$ & \\
Coef. of variation of productivity (in logs) $\times$ Dummy $\theta>1$ & 0.656 & 0.000 \\
& $(0.091)$ & \\
Year dummies & yes \\
Industry fixed effects & yes \\
R-squared & 0.84 & \\
N. of industries & 18 & \\
N. of observations & 270 & \\
\hline \hline
\end{tabular}

Notes: Dependent variable: log of aggregate labor productivity.

Table 4: Robustness check: Firms in the balanced panel

\begin{tabular}{lcc}
\hline \hline & $\begin{array}{c}\text { coef } \\
\text { (s.e) }\end{array}$ & $\begin{array}{c}\text { One side } \\
\text { p-value }\end{array}$ \\
\hline Coef. of variation of productivity (in logs) & -0.078 & 0.076 \\
& $(0.049)$ & \\
Coef. of variation of productivity (in logs) $\times$ Dummy $\theta>1$ & 0.434 & 0.000 \\
& $(0.102)$ & \\
Year dummies & & \\
Industry fixed effects & yes & \\
R-squared & yes & \\
N. of industries & 0.79 & \\
N. of observations & 18 & \\
\hline \hline
\end{tabular}

Notes: Dependent variable: log of aggregate labor productivity. 
Table 5: Robustness check: Sectors with $\theta \neq 1$

\begin{tabular}{lcc}
\hline \hline & $\begin{array}{c}\text { coef } \\
\text { (s.e) }\end{array}$ & $\begin{array}{c}\text { One side } \\
\text { p-value }\end{array}$ \\
\hline & & \\
Coef. of variation of productivity (in logs) & -0.103 & 0.055 \\
& $(0.064)$ & \\
& & \\
Coef. of variation of productivity (in logs) $\times$ Dummy $\theta>1$ & 0.701 & 0.000 \\
& $(0.104)$ & \\
Year dummies & yes & \\
Industry fixed effects & yes & \\
R-squared & 0.81 & \\
N. of industries & 14 & \\
N. of observations & 210 & \\
\hline \hline
\end{tabular}

Notes: Dependent variable: log of aggregate labor productivity. There are four sectors that are excluded because it is not possible to reject that $\theta$ is equal to one in those sectors. 
Table 6: Estimation of $\theta$ by IV

\begin{tabular}{llcccc}
\hline \hline & & \multicolumn{3}{c}{ First Stage (FS) } & \multicolumn{3}{c}{ Second Stage (SS) } \\
& Sectors & coef & sd & $\theta$ & sd( $(\theta$ \\
\hline 1 & Ferric and Non Ferric Metals & 0.457 & 0.046 & 1.601 & 0.221 \\
2 & Non Metallic Products & 0.152 & 0.048 & -3.655 & 1.639 \\
3 & Chemical Products & 0.154 & 0.036 & 3.565 & 1.037 \\
4 & Metallic Products & 0.244 & 0.021 & 0.738 & 0.364 \\
5 & Agricultural and Industrial Machinery & 0.399 & 0.028 & 0.864 & 0.340 \\
6 & Office Machinery, Data Processing Machinery, etc. & 0.217 & 0.067 & 4.855 & 1.482 \\
7 & Electrical Material and Electrical Accessories & 0.444 & 0.029 & 2.323 & 0.281 \\
8 & Vehicles and Motors & 0.208 & 0.020 & -0.767 & 0.549 \\
9 & Other Transport Material & 0.006 & 0.067 & -121.6 & 1312.4 \\
10 & Meat and Meat Products & 0.395 & 0.037 & 0.258 & 0.231 \\
11 & Food and Tobacco & 0.206 & 0.021 & 0.767 & 0.347 \\
12 & Beverages & -0.065 & 0.044 & 3.167 & 3.108 \\
13 & Textiles and Apparels & 0.373 & 0.029 & 0.446 & 0.314 \\
14 & Leather products and shoes & 0.185 & 0.029 & 2.945 & 1.085 \\
15 & Wood and Furniture & 0.215 & 0.023 & 0.797 & 0.574 \\
16 & Paper, Paper Products and Printing Products & 0.296 & 0.026 & -0.037 & 0.214 \\
17 & Plastic Products and Rubber & 0.324 & 0.027 & 1.722 & 0.280 \\
18 & Other Manufactured Products & 0.020 & 0.031 & 5.211 & 11.45 \\
\hline \hline Notes
\end{tabular}

Notes: The first stage equation regress the log of price on log of the price of intermediate inputs and year dummies. The second stage regress the log of real output on the predicted value of price and year dummies. The estimated value of $\theta$ is obtained as minus the coefficient of the predicted value of price in the second stage equation. 
Table 7: Excluded sectors in the IV robustness check

\begin{tabular}{|c|c|c|c|c|}
\hline & Sectors & IV1 & IV2 & IV3 \\
\hline 1 & Ferric and Non Ferric Metals & & & \\
\hline 2 & Non Metallic Products & $\theta<0$ & $\theta<0$ & $\theta<0$ \\
\hline 3 & Chemical Products & & & \\
\hline 4 & Metallic Products & & & \\
\hline 5 & Agricultural and Industrial Machinery & & & \\
\hline 6 & Office Machinery, Data Processing Machinery, etc. & & & \\
\hline 7 & Electrical Material and Electrical Accessories & & $\theta_{O L S}<1 \& \theta_{I V}>1$ & $\theta_{O L S}<1 \& \theta_{I V}>1$ \\
\hline 8 & Vehicles and Motors & $\theta<0$ & $\theta<0$ & $\theta<0$ \\
\hline 9 & Other Transport Material & $\theta<0$ & $\theta<0$ & $\theta<0$ \\
\hline 10 & Meat and Meat Products & & & \\
\hline 11 & Food and Tobacco & & & \\
\hline 12 & Beverages & & & FS fails \\
\hline 13 & Textiles and Apparels & & & \\
\hline 14 & Leather products and shoes & & $\theta_{O L S}<1 \& \theta_{I V}>1$ & $\theta_{O L S}<1 \& \theta_{I V}>1$ \\
\hline 15 & Wood and Furniture & & & \\
\hline 16 & Paper, Paper Products and Printing Products & $\theta<0$ & $\theta<0$ & $\theta<0$ \\
\hline 17 & Plastic Products and Rubber & & & \\
\hline 18 & Other Manufactured Products & & & FS fails \\
\hline
\end{tabular}


Table 8: Robustness check: $\theta$ estimated using IV

\begin{tabular}{|c|c|c|c|c|c|c|}
\hline & $\begin{array}{l}\text { Rob. } \\
\text { coef } \\
\text { (s.e) }\end{array}$ & $\begin{array}{c}\text { Ex. IV1 } \\
\text { One side } \\
\text { p-value }\end{array}$ & $\begin{array}{l}\text { Rob. } \\
\text { coef } \\
\text { (s.e) }\end{array}$ & $\begin{array}{c}\text { Ex. IV2 } \\
\text { One side } \\
\text { p-value }\end{array}$ & $\begin{array}{l}\text { Rob. } \\
\text { coef } \\
\text { (s.e) }\end{array}$ & $\begin{array}{c}\text { Ex. IV3 } \\
\text { One side } \\
\text { p-value }\end{array}$ \\
\hline Coef. of variation of productivity (in logs) & $\begin{array}{c}-0.170 \\
(0.140)\end{array}$ & 0.114 & $\begin{array}{c}-0.136 \\
(0.145)\end{array}$ & 0.174 & $\begin{array}{l}-0.135 \\
(0.143)\end{array}$ & 0.247 \\
\hline Coef. of variation of productivity (in logs) $\times$ Dummy $\theta>1$ & $\begin{array}{c}1.244 \\
(0.146)\end{array}$ & 0.000 & $\begin{array}{c}1.281 \\
(0.151)\end{array}$ & 0.000 & $\begin{array}{c}1.33 \\
(0.157)\end{array}$ & 0.000 \\
\hline Year dummies & yes & & yes & & yes & \\
\hline Industry fixed effects & yes & & yes & & yes & \\
\hline R-squared & 0.89 & & 0.89 & & 0.87 & \\
\hline N. of industries & 14 & & 12 & & 10 & \\
\hline N. of observations & 210 & & 180 & & 150 & \\
\hline
\end{tabular}

Notes: Dependent variable: log of aggregate labor productivity. 